\title{
Fatores atribuídos a assistência de enfermagem aos portadores da infecção pelo vírus do HIV/AIDS
}

\author{
Factors assigned to nursing assistance to people with HIV/AIDS vírus infection
}

\author{
Factores assignados a la atencíon de enfermería a personas com infección por vírus del \\ VIH/SIDA
}

Jaberson de Melo Souza ${ }^{1 \star}$, Leidinalva Pedro Feza ${ }^{1}$, Jabneela Vieira Pereira Vetorazo.

\section{RESUMO}

Objetivo: Este estudo delineou compreender como é realizada a assistência de enfermagem e sua importância na atenção primária aos portadores da infecção pelo vírus do HIV/AIDS. Métodos: Trata-se de uma revisão integrativa da literatura, qualitativa, realizada entre os meses de maio 2019 a junho 2020, nas bases de dados da Literatura LatinoAmericana e do Caribe em Ciências da Saúde (LILACS), Literatura Internacional em Ciências da Saúde (PUBMED), na Biblioteca Eletrônica Científica Online (Scielo) e Biblioteca Virtual em Saúde (BVS), a partir da inclusão de artigos científicos disponíveis na íntegra, em livre acesso, publicados no período entre 2010 a 2020. Resultados: Foram encontrados 114 artigos nas bases de dados, excluídos 82 após a aplicação dos critérios de exclusão, selecionados 32 artigos para serem lidos na íntegra e, ao final, 21 estudos foram incluídos para serem analisados a fim de subsidiar a revisão de literatura. Considerações finais: Verificou-se que a enfermagem atua na assistência de saúde do paciente com infecção pelo HIV/AIDS de forma preventiva evitando disseminação da doença e visando promover a saúde, por meio de orientações, acolhimento, diagnóstico, aconselhamento e acompanhamento terapêutico. Porém, a prática ainda é fraca indicando a necessidade de apoio matricial e especializado.

Palavras-chave: HIV, Assistência centrada no paciente, Atenção básica, Enfermagem.

\begin{abstract}
Objective: This study aimed to understand how nursing care is performed and its importance in primary care for people infected with the HIV / AIDS virus. Methods: This is a qualitative, integrative literature review, carried out between May 2019 and June 2020, in the databases of Latin American and Caribbean Literature in Health Sciences (LILACS), International Literature in Health Sciences. Saúde (PUBMED), at the Online Electronic Scientific Library (Scielo) and Virtual Health Library (VHL), based on the inclusion of scientific articles available in full, in free access, published in the period between 2010 and 2020. Results: Found 114 articles in the databases, 82 were excluded after applying the exclusion criteria, 32 articles were selected to be read in full and, at the end, 21 studies were included to be analyzed in order to support the literature review. Final considerations: It was found that nursing acts in the health care of patients with HIV / AIDS infection in a preventive manner, avoiding the spread of the disease and aiming to promote health, through guidance, reception, diagnosis, counseling and therapeutic monitoring. However, the practice is still weak, indicating the need for matrix and specialized support.
\end{abstract}

Key words: HIV, Patient-centered care, Basic attention, Nursing.

\section{RESUMEN}

Objetivo: Este estudio tuvo como objetivo comprender cómo se realiza el cuidado de enfermería y su importancia en la atención primaria de las personas infectadas por el virus del VIH /SIDA. Métodos: Se trata de una revisión de literatura cualitativa, integradora, realizada entre mayo de 2019 y junio de 2020, en las bases de datos de Literatura Latinoamericana y Caribeña en Ciencias de la Salud (LILACS), Literatura Internacional en Ciencias de la Salud. Saúde (PUBMED), en el Online Biblioteca Científica Electrónica (Scielo) y Biblioteca Virtual en Salud (BVS), a partir de la inclusión de artículos científicos disponibles en su totalidad, en libre acceso, publicados en el período 2010-2020. Resultados: Se encontraron 114 artículos en las bases de datos, 82 fueron excluidos tras aplicar los criterios de exclusión, se seleccionaron 32 artículos para su lectura íntegra y, al final, se incluyeron 21 estudios para ser analizados con el fin de apoyar la revisión de la literatura. Consideraciones finales: Se encontró que la enfermería actúa en el cuidado de la salud de los pacientes con infección por VIH / SIDA de manera preventiva, evitando la propagación de la enfermedad y con el objetivo de promover la salud, a través de la orientación, recepción, diagnóstico, asesoramiento y seguimiento terapéutico. Sin embargo, la práctica aún es débil, lo que indica la necesidad de un apoyo matricial y especializado.

Palabras clave: VIH, Atención dirigida al paciente, Atención básica, Enfermería.

${ }^{1}$ Centro Universitário Aparício Carvalho (FIMCA), Porto Velho - RO. *E-mail: jarbeson_am@hotmail.com 


\section{INTRODUÇÃO}

O Human Immuno deficiency Virus (HIV) é a sigla em inglês para o vírus causador da Síndrome da Imunodeficiência Adquirida (AIDS) em que acomete o sistema imunológico. Quando este adentra o sistema imunológico, as primeiras células a serem atingidas são os linfócitos T CD4. O vírus invade-os e altera seu Desoxyribonucleic acid (DNA), fazendo cópias de si mesmo. Ao multiplicar-se rompem os linfócitos e saem à procura de outros linfócitos T CD4 para infectar. Em razão disso o organismo vai perdendo progressivamente a sua capacidade de defesa, ficando vulnerável a adoecer com mais facilidade e frequência (BRASIL, 2013).

A infecção pelo HIV pode ser dividida em quatro fases clínicas: 1) infecção aguda; 2) fase assintomática, também conhecida como latência clínica; 3) fase sintomática inicial ou precoce; e 4) Acquired Immune Deficiency Syndrome (AIDS) (BRASIL, 2015).

Os exames diagnósticos para a detecção do vírus do HIV são divididos em: detecção de anticorpos, detecção de antígenos, cultura viral e testes de amplificação do genoma do vírus, os sintomas na fase aguda da doença são: febre, fadiga, mialgia, exantema, linfadenopatia, náuseas, êmeses e diarreias entre outros, além de favorecer o aparecimento de doenças oportunistas que agravam o estado de saúde do portador podendo levá-lo ao óbito; existem atualmente medicamentos para o tratamento anti-HIV que inibem a replicação do vírus, bloqueando a ação da enzima transcriptase reversa que age convertendo o RNA viral em DNA como os inibidores da protease que agem no último nível do HIV (BRASIL, 2015).

Atualmente no Brasil, um a cada 10 brasileiros contaminados pelo vírus do HIV é profissional do sexo. Ao passar dos anos este grupo vem apresentando uma considerável prevalência da patologia, cerca de 7 a 8 vezes maior que a população em geral, sendo um dado bastante preocupante. Conjectura-se que há um distanciamento entre o profissional do sexo e do serviço de saúde, devido ao fato da existência do preconceito dos próprios profissionais de saúde, que contribui para que esses índices se tornem cada vez mais altos (FORMENTI L, 2013).

Os profissionais do sexo constituem um público cujo acesso é difícil e sua relação com o serviço de saúde pode estar comprometida devido ao preconceito e entre outros fatores. Compreendemos nosso papel éticosocial enquanto profissionais de saúde e o leque de vulnerabilidades a que eles estão sujeitos; por isso se faz necessário estratégias de educação em saúde para que assim, alcancemos este segmento levando prevenção e promoção da saúde, até que o índice de prevalência do HIV/AIDS não seja mais um dado tão alarmante quanto é na atualidade (COSTA TVA, et al., 2018).

Diante dos fatos, o Conselho Federal de enfermagem afirma que o enfermeiro possui um papel fundamental na prevenção, diagnóstico e acompanhamento dos usuários dos serviços de saúde, em especial na atenção primária, no que tange a vigilância epidemiológica, com a incubência de proporcionar por meio de seus conhecimentos e ações, atuando como protagonista para o planejamento, organização e a operacionalização dos serviços de saúde, bem como a realização de testes rápidos e notificação dos casos (COFEN, 2016).

O Ministério da Saúde pontua a importância da equipe de enfermagem sobre a prevenção do HIV e assistência de pessoas portadores de HIV/AIDS na atenção primária, ressaltando que os mesmos precisam estar bem informados e devidamente capacitados para entenderem a problemática que abrange a assistência desses usuários e adotarem uma postura apropriada, de forma a articular com outros profissionais a assistência dessa clientela (BRASIL, 2005).

Face ao exposto, o presente estudo teve como objetivo de descrever a conduta do enfermeiro na assistência ao portador de infecção HIV/AIDS, conforme descritos na literatura.

\section{MÉTODOS}

Trata-se de uma revisão integrativa da literatura, utilizada por seu potencial de organização, síntese de conhecimentos e identificação de lacunas que contribuem na análise crítica de um objeto de estudo proposto. Para isso, seguiu-se os seguintes passos para seu desenvolvimento: formulação da questão norteadora; 
busca na literatura; extração dos dados dos estudos selecionados; avaliação dos estudos; interpretação e síntese dos resultados; apresentação da revisão integrativa (MENDES KDS, et al., 2008).

Para responder ao objetivo do presente estudo, formulou-se a seguinte questão norteadora: "O que as produções científicas disponíveis na literatura nacional, abordam referente a fatores atribuidos a assistência de enfermagem na assistência primaria aos portadores da infecção pelo vírus do HIV/AIDS?"

O levantamento bibliográfico foi realizado nas bases de dados da Literatura LatinoAmericana e do Caribe em Ciências da Saúde (LILACS), Literatura Internacional em Ciências da Saúde (PUBMED), na Biblioteca Eletrônica Científica Online (Scielo) e Biblioteca Virtual em Saúde (BVS), o que possibilitou a busca por estudos publicados no cenário nacional.

Para a seleção dos estudos, optou-se pela inclusão de artigos científicos disponíveis na íntegra, em livre acesso, publicados no período entre 2010 a 2020, nos idiomas português, bem como aqueles que, após leitura do título e resumo, abordassem aspectos relacionados à temática do estudo. Foram excluídos os artigos duplicados, artigos de revisão, de reflexão/debates, monografias, dissertações, teses, comentários, editoriais e cartas. Os estudos elegíveis foram lidos na íntegra, a fim de incluir ou não, aqueles que conseguissem responder à questão norteadora. A interpretação e síntese dos resultados encontrados será apresentada em uma tabela contendo os autores, ano, local e periódico de publicação, bem como os principais resultados quanto a assistência de enfermagem nas na assistência primaria aos portadores da infecção pelo vírus do HIV/AIDS.

\section{RESULTADOS}

Foram encontrados 114 artigos nas bases de dados, dos quais em um primeiro momento, 82 artigos foram excluídos após aplicação dos critérios: sendo excluídos 08 estudos por estarem indisponíveis, 09 por estarem inferiores ao período previamente selecionado, 19por estarem duplicados, 13 por serem artigos de revisão, 14 por serem de outro idioma, 11 por serem teses e dissertações, 8 por apresentarem apenas título e resumo. Após a leitura de título e resumo, 32 artigos foram selecionados para leitura na íntegra, e depois de terem sidos lidos na íntegra, 11 artigos foram excluídos, o que possibilitou ao final, a inclusão de 21 artigos para serem analisados a fim de subsidiar a revisão de literature (Figura 1).

Figura 1- Fluxograma das etapas para a seleção dos artigos desta revisão integrativa, 2020.

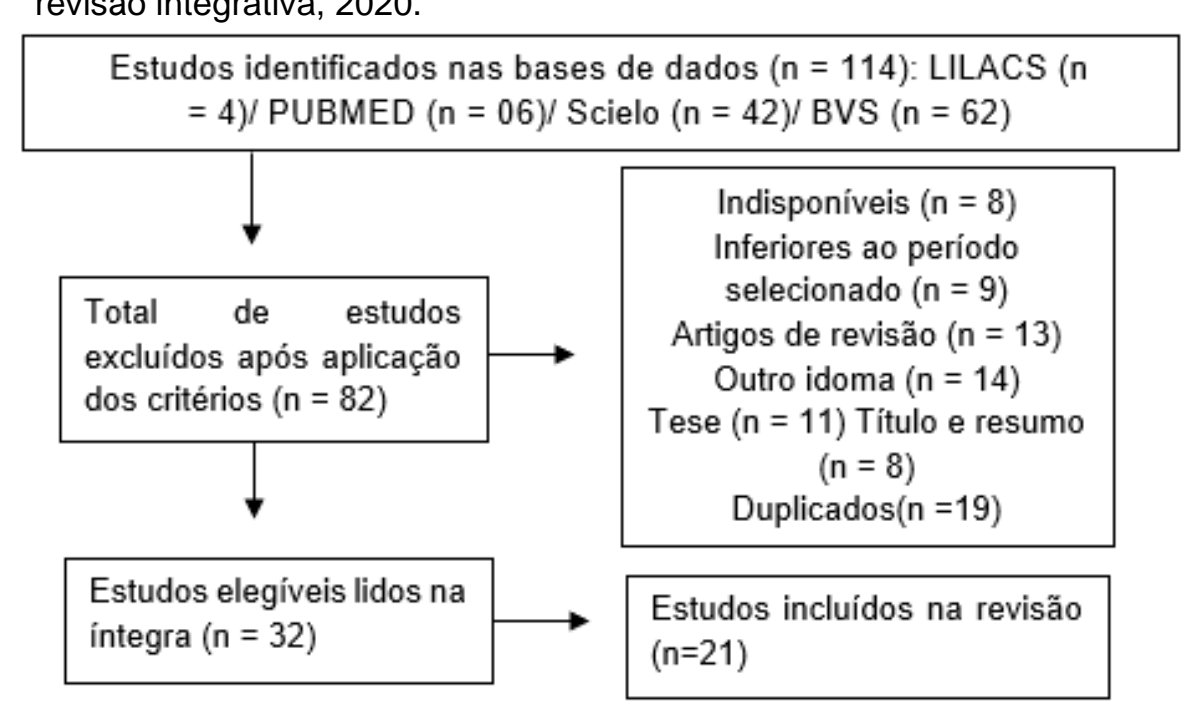

Fonte: SOUZA JM, et al., 2021.

Dos artigos incluídos na revisão, a maioria foi publicado no idioma português (99\%), e apenas um no idioma inglês (1\%), que foi traduzido. Quanto ao tipo de estudo, identificou-se majoritariamente, pesquisas do tipo observacionais (28\%), Experimental (5\%), transversais analíticos (14\%), transversais com abordagens qualitativa (29\%)/quantitativa (24\%) (Quadro 1). 


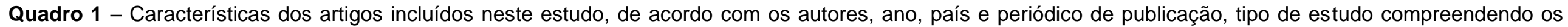
fatores atribuidos a assistência de enfermagem na assistência primária aos portadores da infecção pelo vírus do HIV/AIDS.

\begin{tabular}{|c|c|c|c|}
\hline Autores & Períodico e ano de publicação & Tipo de Estudo & Vertente do artigo \\
\hline SILVA LMS, et al. & $\begin{array}{l}\text { Texto \& Contexto - } \\
\text { Enfermagem, } 2013\end{array}$ & Observacional & $\begin{array}{l}\text { Cotidiano de mulheres após contágio pelo } \\
\text { HIV/AIDS: subsídios norteadores da } \\
\text { assistência de enfermagem. }\end{array}$ \\
\hline PALÁCIO MB, et al. & Revista Psico, 2012 & Tranversal qualitativo & $\begin{array}{c}\text { O Cuidado em HIV/AIDS e a Atenção Primária } \\
\text { em Saúde: Possibilidades de Integração da } \\
\text { Assistência }\end{array}$ \\
\hline FORMOZO GA e OLIVEIRA DC & $\begin{array}{l}\text { Revista Brasileira de } \\
\text { Enfermagem, } 2010\end{array}$ & Observacional & $\begin{array}{c}\text { Representações sociais do cuidado prestado } \\
\text { aos pacientes soropositivos ao HIV }\end{array}$ \\
\hline SOUZA MSMR e FREITAS MF & $\begin{array}{l}\text { Revista } \\
\text { Latino-Americana de } \\
\text { Enfermagem, } 2010\end{array}$ & Tranversal qualitativo & $\begin{array}{l}\text { Representações de profissionais da atenção } \\
\text { primária sobre risco ocupacional de infecção } \\
\text { pelo HIV. }\end{array}$ \\
\hline SOUZA MSM e FREITAS MF & $\begin{array}{c}\text { Revista Mineira de } \\
\text { Enfermagem (REME), } 2012\end{array}$ & Tranversal analítico & $\begin{array}{c}\text { Aconselhamento em HIV/AIDS: representações } \\
\text { dos profissionais que atuam na atenção } \\
\text { primária à saúde }\end{array}$ \\
\hline MELO EA, et al. & $\begin{array}{l}\text { Revista Panamericana de Salud } \\
\text { Pública, } 2018\end{array}$ & Tranversal qualitativo & $\begin{array}{l}\text { Cuidado, HIV/Aids e atenção primária no Brasil: } \\
\text { desafio para a atenção no Sistema Único de } \\
\text { Saúde? }\end{array}$ \\
\hline COLAÇO AD, et al. & $\begin{array}{l}\text { Texto \& Contexto - } \\
\text { Enfermagem, } 2019\end{array}$ & Tranversal qualitativo & $\begin{array}{l}\text { O cuidado à pessoa que vive com HIV/AIDS na } \\
\text { atenção primária à saúde }\end{array}$ \\
\hline RANGEL JF, et al. & $\begin{array}{c}\text { Revista } \\
\text { Interface - Comunicação, Saúde, } \\
\text { Educação, 2019 }\end{array}$ & Observacional & $\begin{array}{l}\text { A assistência aos portadores de hiv/aids na } \\
\text { atenção básica de serviços do sistema único. }\end{array}$ \\
\hline COUTINHO MFC, et al. & $\begin{array}{c}\text { Revista } \\
\text { Saúde Debate, } 2018\end{array}$ & $\begin{array}{l}\text { Tranversal } \\
\text { qualitativo }\end{array}$ & $\begin{array}{c}\text { Tratamentoantirretroviral: adesão e a influência } \\
\text { da depressão em usuários com HIV/Aids } \\
\text { atendidos na atenção primária }\end{array}$ \\
\hline FEITOZA LML, et al. & $\begin{array}{c}\text { Revista Amazônia: Science \& } \\
\text { Health, } 2020\end{array}$ & Tranversal analítico & $\begin{array}{c}\text { Principais características da atuação dos } \\
\text { profissionais de enfermagem da atenção } \\
\text { primária em saúde na assistência ao paciente } \\
\text { soropositivo }\end{array}$ \\
\hline
\end{tabular}




\begin{tabular}{|c|c|c|c|}
\hline Autores & Períodico e ano de publicação & Tipo de Estudo & Vertente do artigo \\
\hline FREITAS CC, et al. & $\begin{array}{c}\text { Research, } \\
\text { Society and Development, } 2020\end{array}$ & Tranversal quantitativo & $\begin{array}{c}\text { Avaliação do Controle do HIV/Aids na Atenção } \\
\text { Primária em Palmas/TO }\end{array}$ \\
\hline SOUZA LRB, et al. & $\begin{array}{c}\text { Revista } \\
\text { Brasileira Multidisciplinar, } 2020\end{array}$ & Tranversal quantitativo & $\begin{array}{l}\text { Percepções dos enfermeiros mediante a } \\
\text { realização do teste rápido de HIV/AIDS na } \\
\text { atenção primária à saúde }\end{array}$ \\
\hline OLIVEIRA JAS E AFONSO TM & $\begin{array}{l}\text { Congresso Internacional de } \\
\text { Enfermagem (CIE), } 2017\end{array}$ & Tranversal qualitativo & $\begin{array}{l}\text { O Teste Rápido para o Diagnostico de HIV na } \\
\text { Atenção Primária à Saúde e a importância da } \\
\text { atuação do Enfermeiro }\end{array}$ \\
\hline SILVA O, et al. & Enfermagem em foco, 2018 & Transversal analítico & $\begin{array}{c}\text { As atuações do enfermeiro relacionadas ao } \\
\text { teste rápido anti-hiv diagnóstico: uma reflexão } \\
\text { de interesse da enfermagem e da saúde } \\
\text { pública. }\end{array}$ \\
\hline SANTOS SMP, et al. & Escola Anna Nery, 2019 & Tranversal quantitativo & $\begin{array}{l}\text { Roteiros de sexualidade construídos por } \\
\text { enfermeiros e a interface com a atenção em } \\
\text { infecções sexualmente transmissíveis/HIV. }\end{array}$ \\
\hline MAGNOBOSCO GT, et al. & Escola Anna Nery, 2018 & Observacional & $\begin{array}{l}\text { Assistência ao HIV/aids: análise da integração } \\
\text { de ações e serviços de saúde }\end{array}$ \\
\hline BEZERRA VP, et al. & $\begin{array}{l}\text { Revista Ciência, Cuidado e } \\
\text { Saúde, } 2016\end{array}$ & Observacional & $\begin{array}{l}\text { Ações de prevenção do HIV e de promoção à } \\
\text { saúde no contexto da AIDS pela estratégia } \\
\text { saúde da família em João Pessoa-PB }\end{array}$ \\
\hline TAQUETTE SR, et al. & $\begin{array}{l}\text { Revista Ciência \& Saúde } \\
\text { Coletiva, } 2017\end{array}$ & Tranversal quantitativo & $\begin{array}{c}\text { Percepção de pacientes com AIDS } \\
\text { diagnosticada na adolescência sobre o } \\
\text { aconselhamento pré e pós-teste HIV realizado }\end{array}$ \\
\hline VAL LF e NICHIATA LYI & $\begin{array}{c}\text { Revista Escola de } \\
\text { Enfermagem da USP, } 2014\end{array}$ & Observacional & $\begin{array}{c}\text { A integralidade e a vulnerabilidade } \\
\text { programática às DST/HIV/AIDS na Atenção } \\
\text { Básica }\end{array}$ \\
\hline $\begin{array}{c}\text { CARNEIRO AJS e COELHO } \\
\text { EAC }\end{array}$ & $\begin{array}{l}\text { Ciência \& Saúde Coletiva, } \\
\qquad 2010\end{array}$ & Experimental & $\begin{array}{l}\text { Aconselhamento na testagem anti-HIV no ciclo } \\
\text { gravídico-puerperal: o olhar da integralidade }\end{array}$ \\
\hline PREVIATI SM, et al. & $\begin{array}{l}\text { Journal Health Biol Science, } \\
2019 .\end{array}$ & Tranversal qualitativo & $\begin{array}{l}\text { A importância do aconselhamento no exame } \\
\text { rápido de HIV em gestantes durante o pré-natal }\end{array}$ \\
\hline
\end{tabular}

Fonte: SOUZA JM, et al., 2021. 


\section{DISCUSSÃO}

Diante da literatura consultada, pode-se compreender os fatores atribuidos a assistência de enfermagem na atenção primária aos portadores da infecção pelo vírus do HIV/AIDS.Os estudos apontaram que a assistência de enfermagem no atendimento a pacientes com HIV/AIDS na atenção primária, baseiam-se em consultas, acolhimento, testes rápidos, aconselhamento, realização de grupos de adesão, bem como realizam a visita domiciliar e notificação epidemiológica (VAL LF e NICHIATA LYI, 2014; BEZERRA VP, et al., 2016; FEITOZA LML, et al., 2020).

Evidenciou-se que ao atender pacientes soropositivos os profissionais da Atenção Primária de Saúde (APS), visam a promoção e a prevenção dos agravos a saúde desse público. Sua assistência consiste desde o conhecimento da patologia em si, diagnóstico, explicar e acompanhar no tratamento, destacando-se nesse momento o aconselhamento de forma humanizada e acolhedora (FEITOZA LML, et al., 2020; SOUZA MSMR e FREITAS MF, 2012; RANGEL JF, et al., 2014).

No estudo de Souza MSMR e Freitas MF (2012), foi descrito que alguns profissionais da enfermagem praticam o aconselhamento, todavia de forma limitada, oferecendo somente o teste anti-HIV e prestando esclarecimento sobre ele, sem interagir emocionalmente ou estabelecer um elo de confiança com o paciente. Outro ponto que merece destaque é o momento em que o paciente recebe o resultado do exame, que segundo Colaço AD, et al., (2019), o enfermeiro compreende que o diagnóstico do HIV gera grande tensão e ansiedade para os usuários, que é motivado especialmente pelo estigma que se tem sobre a doença, tal informação demanda preparo do enfermeiro para saber lidar com essa informação e, principalmente, com a reação do paciente.

Portanto, tanto no estudo de Souza MSMR e Freitas MF (2012), como no estudo de Colaço AD, et al., (2019), afirma-se que existe um distanciamento entre a forma como os profissionais da enfermagem agem e o sobre como deve ser a assistência prestada, preconizada pelo Conselho Federal de Enfermagem (COFEN) e pelo Ministério da Saúde.

Trata-se de uma falha na forma de atendimento, pois, com base, no estudos de Silva LMS et al., (2013), a assistência de enfermagem precisa acolher às necessidades biopsicossociais, considerando a os sentimentos dos paciente soropositivos, tais quais vários conflitos mentais,como o medo de contaminar os demais membros da família, o desejo de se isolar, o sentimento de culpa, e as questões relativas a reprodução. Logo, Feitoza LML, et al. (2020), afirmam que o enfermeiro precisa estar preparado para acolher o paciente, frente as fatores psicológicos, físicos e espirituais, bem como abordar o preconceito social devido à incompreensão da infecção; o histórico de doenças imunológicas que favorecem a ação do vírus no organismo; a crença e a fé pelo seu grande potencial colaborativo ao tratamento.

Já Oliveira JAS e Afonso TM (2017), explicam que, é função da enfermagem promover o aconselhamento humanizado e bem desenvolvido, possibilitando que os pacientes se sintam mais seguros e apoiados, com uma maior expectativa de vida, quando comparados aqueles que recebem somente instruções sobre o que devem fazer de forma sistemática.

Em conformidade com Silva O (2011), Souza MSMR e Freitas MF (2012), afirmam ser importante que o profissional da enfermagem trabalhe de maneira informativa, pedagógica, humanizada e articulada, quando necessário busque formas de apoio social e serviços de assistência de qualidade e resolutividade considerando, que na atenção primária, o foco é para orientação e informações, de forma preventiva. O enfermeiro capacitado executa um aconselhamento humanizado e sensível, tornando o processo de escuta ativa uma relação de confiança, diminuindo assim dúvidas, medos e estressores, decorrentes do resultado positivo ou negativo do teste rápido (SILVA O, 2011).

O cuidado ao paciente com HIV na atenção primária pode ser aprimorado, quando o enfermeiro junto a equipe são capacitadas a criar Projetos Terapêuticos Singular (PTS), visando sistematizar e buscar meios de melhorar esse cuidado, apoio matricial e acesso a serviços especializados para seus pacientes (PALÁCIO MB, et al., 2012). 
Nos últimos anos, novas diretrizes nacionais e experiências locais vem tratando do necessidade de atenção e capacitação dos profissionais da atenção primária quanto ao tema do HIV/AIDS, destacando o importante papel das equipes de saúde nesse contexto e pontuando a necessidade de fortalecer a atenção primária e sua integração nas Redes de Atenção à Saúde (RAS) (MELO EA, et al., 2018).

Pode-se verificar indicações de que a cronicidade assumida pelo HIV/AIDS impõe sobrecarga aos serviços de saúde, de forma a expor as falhas que existem no processo de planejamento da assistência integrada, sendo encarado como um desafio para os enfermeiros e todos os profissionais que trabalham na atenção primária. De forma que, considera-se necessário o apoio matricial e uma articulação constante das práticas clínicas, visando garantir a continuidade e a globalidade da assistência prestada (MAGNABOSCO GT, et al., 2018; PALÁCIO MB, et al., 2012; COLAÇO AD, et al., 2019).

Bezerra VP, et al. (2016), também pactuam com esse entedimento, destacando a realidade da enfermagem em relação a assistência prestada aos pacientes referidos. Segundo os autores supracitados, não há uma rotina e um planejamento para os temas a serem expostos nas ações de educação em saúde no âmbito da infecção pelo HIV, dificilmente há formação de grupos voltados somente para esses pacientes, e as informações e orientações que são dadas, se limitam aos usuários que comparecem as consultas de enfermagem, sobretudo, as mulheres que vem para o pré-natal e para fazer exame preventivo do colo uterino. Portanto, apesar de saberem da importância de abordagem do tema HIV/AIDS, é tratada com focos em campanhas anuais: períodos de Carnaval e dia Mundial de Combate a Aids.

O fato de que existe uma distancia entre a teoria sobre a assistência prestada pelo profissional da enfermagem na Atenção primária e a prática da enfermagem é também citada nas pesquisas de Taquette SR, et al. (2017), sobre a percepção dos usuários sobre o atendimento da enfermagem, que afirmam apesar de ser determinado um atendimento ao usuário com base no acolhimento, apoio emocional, explicações sobre a AIDS doença e seu tratamento, os pacientes declaram que tiveram dificuldade de lembrar sobre o diálogo estabelecido, sobre as orientações recebidas quando lhes foram solicitados teste do HIV e seu resultado, evidenciando deficiência no aconselhamento por parte do profissional de saúde, condescendendo com os estudos de Val FL e Nichiata LYI, (2014) que indicam falhas no momento do aconselhamento, sendo relatado que as consultas foram realizadas rápida e mecanicamente, sem oferecer uma assistência humanizada.

Muitos enfermeiros declararam o risco percebido de contaminação e a necessidade de uma cautela redobrada neste cuidar devido. Neste sentido, Formozo GA e Oliveira DC (2010), ressaltam que a cautela, quando mal abordada, pode gerar uma barreira para o relacionamento entre o profissional e o cliente, mas que, se executados da forma adequada, os equipamentos de segurança facilitam o cuidado, pois, possibilitam a proximidade entre enfermeiro e paciente, sem que isto represente risco de contaminação para qualquer uma das partes.

Os achados mostram a importância de capacitação frequente em serviço, bem como rodas de conversas entre os profissionais, para que expressem suas dúvidas e falem das suas experiências a fim de que desmistifiquem as fantasias que existem em relação à evolução da AIDS, rompam estereótipos e preconceitos, que venham gerar atitudes incorretas e prejudiquem o processo de trabalho na atenção primária, visto que o baixo investimento em capacitações nesse sentido pode contribuir com impacto negativo nas relações interpessoais e na assistência ao portador do HIV/AIDS (SOUZA MSMR e FREITAS MIF, 2010; TAQUETTE SR, et al., 2017; SANTOS SMP, et al., 2019; FREITAS CC, et al., 2020).

Neste sentido, Previati SM et al., (2019) reafirmam a necessidade de capacitação constante para a enfermagem, a fim de que o mesmo esteja livre das barreiras do preconceito e do pré-julgamento para que consiga, por meio da educação em saúde, alcançar o seu maior objetivo: a confiança e a melhora da saúde do paciente. Além de incitar o desenvolvimento de uma rede de proteção e suporte aos pacientes e familiares, de maneira a se subsidiar uma assistência acolhedora que venha a ter um desfecho terapêutico adequado (COUTINHO MFC, et al., 2018; SOUZA LRB, et al., 2020). 


\section{CONSIDERAÇÕES FINAIS}

A enfermagem atua na assistência do paciente com infecção pelo HIV/AIDS de forma preventiva evitando disseminação da doença e visando promover a saúde, atuando prioritariamente por meio de orientações, acolhimento, diagnóstico, aconselhamento e acompanhamento terapêutico. Todavia, evidenciou-se que na prática, a assistência ainda é fraca, com foco em campanhas anuais, indicando a necessidade de apoio matricial e especilializado para aperfeiçoar a assistência prestada. Nota-se que grande parte das dificuldades para 0 atendimento adequado poderiam ser superadas se houvesse capacitações contínuas de aperfeiçoamento, pois a categoria precisa estar apto para o acolhimento ao paciente, respeitando os aspectos fisiológicos, psicológicos, culturais e até espirituais, pois, como foi visto nos estudos, todos esses aspectos influenciam na melhora do paciente.

\section{REFERÊNCIAS}

1. BEZERRA VP, et al. Ações de prevenção do hiv e de promoção à saúde no contexto da aids pela estratégia saúde da família em João Pessoa-PB. Ciência, cuidado e saúde, 2016, 15(2): 343-349.

2. BRASIL. Ministério da Saúde. Biblioteca Virtual em Saúde. Aids: etiologia, clínica, diagnóstico e tratamento. Brasília, 2015.

3. BRASIL. Ministério da Saúde. Biblioteca Virtual em Saúde.Departamento de Doenças de Condições Crônicas e Infeccões Sexualmente Transmissíveis. O que é HIV. Brasília, 2013.

4. BRASSIL. Ministério da Saúde. Manual de Orientação básica para equipe de enfermagem sobre a prevenção do HIV e assistencia de pessoas portadores de HIV e Aids. Brasília, 2005.

5. CARNEIRO AJS e COELHO EAC. Aconselhamento na testagem anti-HIV no ciclo gravídico- puerperal: o olhar da integralidade. Ciência \& Saúde Coletiva, 2010, 15(1): 1217-1226.

6. COFEN (Conselho Federal de Enfermagem). Parecer de Conselheiro no 259/2016. Rio de Janeiro, 2016.

7. COLAÇO AD, et al. O cuidado à pessoa que vive com HIV/AIDS na atenção primária à saúde. Texto \& Contexto Enfermagem, 2019, 28:e20170339.

8. COSTA TVA, et al. Preconceito, relações familiares e práticas de saúde em profissionais do sexo: uma abordagem qualitativa. Revista Médida de Minas Gerais, 2018, 28 (supl 4): S54-S62.

9. COUTINHO MFC, et al. Tratamento antirretroviral: adesão e a influência da depressão em usuários com HIV/Aids atendidos na atenção primária. Saúde Debate, 2018, 42 (116): 148-161.

10. FEITOZA LML, et al. Principais características da atuação dos profissionais de enfermagem da Atenção Primária em Saúde na assistência ao paciente soropositivo. Revista Amazônia: Science \& Health, 2020, 8(2): 2-23.

11. FORMENTI L. De cada dez soropositivas, uma é prostituta. Brasília, 2013.

12. FORMOZO GA e OLIVEIRA DC. Representações sociais do cuidado prestado aos pacientes soropositivos ao HIV. Revista Brasileira de Enfermagem, 2010, 63(2):230-237.

13. FREITAS CC, et al. Avaliação do Controle do HIV/Aids na Atenção Primária em Palmas/TO. Research, Society and Development, 2020, 9(9): e372997126.

14. MAGNABOSCO GT, et al. Assistência ao HIV/aids: análise da integração de ações e serviços de saúde. Escola Anna Nery, 2018, 22(4): e20180015.

15. MELO EA, et al. Cuidado, HIV/Aids e atenção primária no Brasil: desafio para a atenção no Sistema Único de Saúde? Revista Panamericana de Salud Pública, 2018, 42.

16. MENDES KDS, et al. Revisão integrativa: método de pesquisa para a incorporação de evidências na saúde e na enfermagem. Texto \& Contexto - Enfermagem, 2008, 17(4): 758-764.

17. OLIVEIRA JAS e AFONSO TM. O Teste Rápido para o Diagnostico de HIV na Atenção Primária à Saúde e a importância da atuação do Enfermeiro. Congresso Internacional de Enfermagem (CIE), 2017, 1(1).

18. PALÁCIO MB, et al. O cuidado em HIV/AIDS e a atenção primária em saúde. Psico, 2013, 43(3): 360-367.

19. PREVIATI SM, et al. A importância do aconselhamento no exame rápido de HIV em gestantes durante o pré-natal. Journal of Health Biological Sciences, 2018, 7(1): 75-81.

20. RANGEL JF, et al. A assistência aos portadores de hiv/aids na atenção básica de serviços do sistema único. Revista Interface - Comunicação, Saúde, Educação, 2014, 3(1).

21. SANTOS SMP, et al. Roteiros de sexualidade construídos por enfermeiros e a interface com a atenção em infecções sexualmente transmissíveis/HIV. Escola Anna Nery, 2019, 23(4): e20190078.

22. SILVA LMS, et al. Cotidiano de mulheres após contágio pelo HIV/AIDS: subsídios norteadores da assistência de enfermagem. Texto \& Contexto - Enfermagem, 2013, 22(2): 335-342.

23. SILVA O, et al. As atuações do enfermeiro relacionadas ao teste rápido anti-hiv diagnóstico: uma reflexão de interesse da enfermagem e da saúde pública. Enfermagem em Foco, 2011, 2(1):58-62.

24. SOUZA LRB, et al. Percepções dos enfermeiros mediante a realização do teste rápido de HIV/AIDS na atenção primária à saúde. Revista Brasileira Multidisciplinar, 2020, 23(2).

25. SOUZA MSMR e FREITAS MIF. Aconselhamento em HIV/AIDS: representações dos profissionais que atuam na atenção primária à saúde. Revista Mineira de Enfermagem, 2012, 16(1): 18-24.

26. SOUZA MSMR e FREITAS MIF. Representações de profissionais da atenção primária sobre risco ocupacional de infecção pelo HIV. Revista Latino-Americana de Enfermagem, 2010, 18(4): [08 telas].

27. TAQUETTE SR, et al. Percepção de pacientes com AIDS diagnosticada na adolescência sobre o aconselhamento pré e pós-teste HIV realizado. Ciência \& Saúde Coletiva, 2017, 22(1): 23-30.

28. VAL LF e NICHIATA LYI. A integralidade e a vulnerabilidade programática às DST/HIV/AIDS na Atenção Básica. Revista da Escola de Enfermagem da USP, 2014, 48(1): 149-155. 